\title{
Which Comes First: “Tourism or Oenogastronomy?”
}

\author{
Ruhet Genç \\ Turkish-German University (TGU), Istanbul, Turkey
}

\begin{abstract}
Nutrition is a crucial driving motive of human beings. When someone wants to increase his/her quality of life (QOL), he/she needs to consider some other factors additional to nutrition. Varieties and presentations of food and beverage (F\&B) make it possible for us to enjoy them. Either they will be transported to the consumers in order to fulfill their basic needs or they may go and discover them in their natural environment. Another option is originating oenogastronomy tourism especially value added by side-trips, entertainment, and other activities. By converting terroirs into tourist destinations, we can attract people and in connection therewith reorganization of the aimed places can be triggered via having a vast number of people visiting the created destinations. While this adventurous path is flourishing, we deal with some new born concepts such as oenogastronomy, slow food, hedonism, and so on. Depending on the country, culture, and organizational background, these interactive changes take place. Research question of this paper resembles the chicken and an egg situation: "To what extend oenogastronomy serves for tourism and/or tourism serves for oenogastronomy?”. Studies show the reciprocal relationship between the two concepts. Their interrelated connections affect each other's existence and size. Traveling and tourism are kind of leisure which involves getting away from various routines. Especially in a terroir where the grape production is possible, oenogastronomy flourishes as a crucial branch of tourism which directly increases leisure variety by affecting all the other related sectors. Actually, when tourists consume wine, the aim will be reached easier.
\end{abstract}

Keywords: oenogastronomy, wine tourism, gastronomy tourism, cultural tourism, hedonism, quality of life (QOL), sustainability

\section{Introduction}

The flourishing area of wine and agro-food tourism is worth considering as one of the main branches of tourism, especially in the area where we can directly produce wine. Dealing with this kind of tourism is a value-added practice for tourism in general and an additional meaningful choice for tourists. In that sense, the aim of this paper is twofold: (1) to contribute to the studies of wine and food leisure; and (2) to show the importance of tourism for the advancement of wine and food segment.

Food and drink are not only related as nutritious value but they also have cultural and traditional significances. This means also for us to gain an insight through our senses into another culture and other people's way of life. Traveling and tourism are form of leisure that involves "getting away from it all". It means that we leave all routines and negatives behind us and enjoy ourselves more. In this connection, food and drink can facilitate to reach our aim. The sensory features of food and drink enable tourists to have different experiences. Almost all milestone activities do include some kind of food and drink experiences depending on the budget, culture, time allowed, host and guest expectations, and understanding of such an event, i.e., family reunions.

Ruhet Genç, associate professor, Faculty of Economics \& Administrative Sciences, Turkish-German University (TGU). Email: drgench@gmail.com. 


\section{Food and Beverage (F\&B) and Tourism}

Food has always been part of tourism activities both as being a necessity of human beings and as being performance in relation with hotels and restaurants. Tourism can be described as a set of relaxation and/or entertainment activities of humankind that have economical, sociological, and psychological side, enabling globalization process, and promoting the world peace with the aim of feeling ourselves better by understanding others through their cultural products, and increasing our quality of life (QOL). Any tourism activity including food and drink experiences can be organized as an unforgettable event.

The joy of consuming delicious food and drink shows us that it has a deeper meaning for us rather than its importance for keeping our physical and mental health. Also, food and drink are important aspects of culture that they belong to. Such as the variety of languages, there are plenty of different dishes and recipes all over the world. According to Hall and Mitchell, the relationship between F\&B and tourism is described as a visit to primary and secondary food producers, food festivals, restaurants, and specific locations for which food and experience are the primary motivating factors for travel.

Gastronomy has its roots in the ancient times. The etymology of the word indicates that it is related with our digestive system: gaster means stomach and nomas means rules. Thanks to the advancement in centuries, gastronomy has become a broadened concept with its own branches.

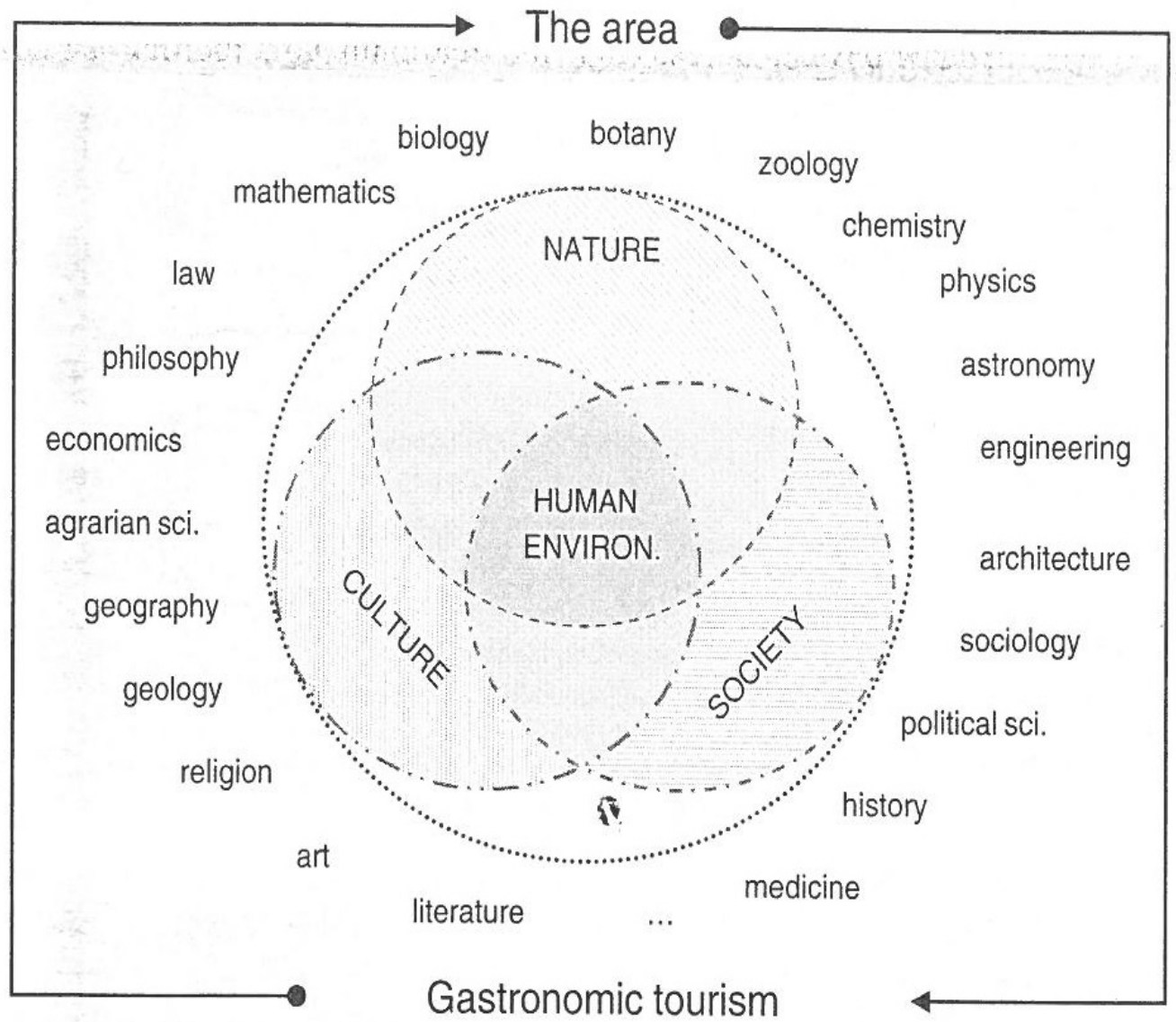

Figure 1. An interdisciplinary approach to interpret the landscape and create multiple experiences in a gastronomic destination. Source: Croce and Perri (2010). 
Gastronomic tourism is an interdisciplinary subject. In order to realize its size, we need to use scientific, recreational methodologies and approaches. Figure 1 shows the multidisciplinary relations. Whether it is a gastronomic or oenogastronomic destination, they all need a deep analysis of geographic models and related theories should be applied to understand the full appreciation of the destination. As the saying "fish discovers the water last" stipulates, stakeholders in a destination never have a clear picture of the whole reality. By analyzing and describing destinations in general, with all the necessary details, not only stakeholders can have a good sense of the clear picture but also they can have a good opportunity to create rules, regulations, and policies for tourism.

\section{Oenogastronomic Tourism}

The most recent type of relationship between F\&B and tourism is formalized under the concept of oenogastronomic tourism. Although most of tourist activities include F\&B, this tourist activity has food and drink as its push factor. Oenogastronomy is the branch of gastronomy that has been dealing with wine. Wine is a very elaborate subject with all of its production, consumption ceremonies, and rituals. Oenogastronomic tourists not only drink wine but also "visit vineyards and wineries, attend wine shows and festivals, learn and taste wine made from local grapes and discover the terroir in which vines are cultivated" (Croce \& Perri, 2010, p. 144). In that sense, it is a branch of tourism that has a cultural and sociological value. While tourists are gaining sight regarding wine in general, oenogastronomic tourism enables the professionals to understand better the concept of F\&B. Oenogastronomy and the related parties have a reciprocal relationship in which expectations of the tourists can be fulfilled by host community while tourists have the freedom to express their will about the offered goods.

\section{Tourist Motivation and Behavior}

Oenogastronomy is one of the few activities that included in all kinds of tourist motivation. Touristic activity is conceptualized as a step of expectations of tourists. Swarbrooke and Horner (1999) presented a comprehensive model (see Figure 2) for tourist motivation in six headings, namely, personal, physical, emotional, status, personal development, and cultural. F\&B enables physical relaxation and provides a cultural experience if we are experiencing something new either/or presented in a new way or in a different setting. F\&B is included in almost all kinds of visits and the socialization of eating and drinking is a way to make new friends, foster existing relationships, get new habits, learn different issues, gain a new way of thinking, and also reshape our mind and lifestyle. Experiencing a new taste is a satisfying personal development. There are different types of F\&B tourism that involve an adventurous or nostalgic direction. Romantic moments of couples are generally shared via consuming F\&B before anything else. Eating and drinking habits are signs of status. No matter tourists are psychocentrics, allocentrics, or midcentrics, they all are putting F\&B experiences as a vital part of their tourism activities (Plog, 1991).

There are different factors behind various tourist behaviors. In the tourist behavior literature, age is considered as a significant variable that influences individual motivation for touristic activity, expectancies, and consumption behavior (Genç, 2012a). Subjective well-being (SWB) is a construct that has been examined over many centuries and has been defined in ethical, theological, political, economical, and psychological terms (Lewinsohn, Redner, \& Seeley, 1991). As a result, there are several other adjectives used to label it, including happiness, QOL, and life satisfaction (Gilbert \& Abdullah, 2004). Demographic variables, psychological factors, social and cultural characteristics are important for tourist behavior and directly affect their QOL. A brief look at 
the frameworks by which QOL is defined helps to have an idea on what the concept is all about (Genç, 2012b). Tourists' gender, nationality, social status are all determinant in their behavior. Oenogastronomic tourists are essentially cultural ones who prefer to go to wine and food destinations. Indeed, good wine and pairing food are not coming to our table by coincidence. One has to be well educated about wine and food in order to make the best choice for her/himself. Since taste is a personal matter, there is no description for the best which might suit all. However, good education and meaningful experiences enable us to make the best choice for ourselves.

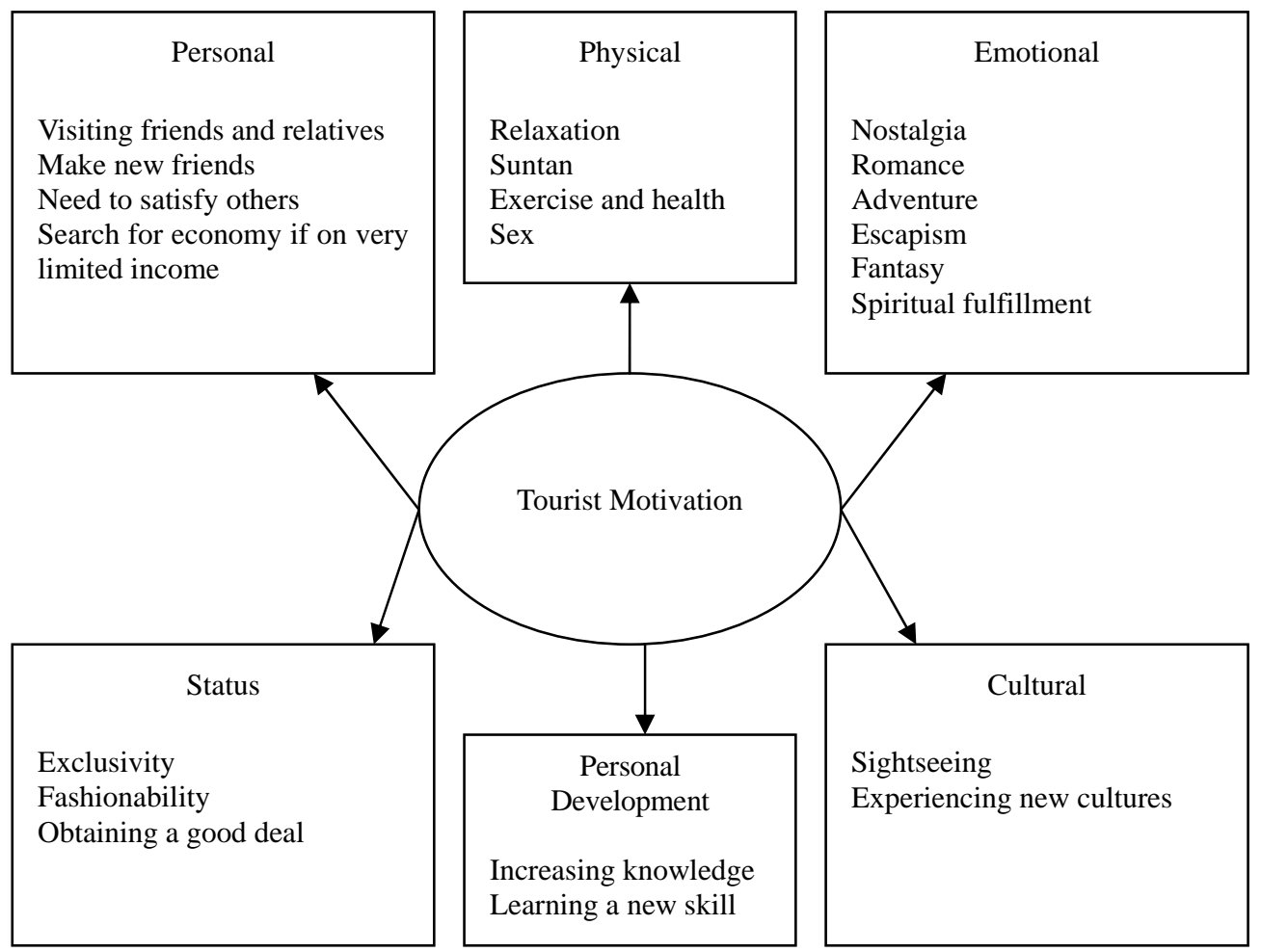

Figure 2. Elements of tourist motivation. Source: Swarbrooke and Horner (1999).

\section{Wine and Dine}

Taste is one of the main points of oenogastronomic tourism. Although it is a personal matter and there is no standard to measure it, there is no accepted best or worst. Taste and different experiences become a vital part of the whole picture rather than nourishment. Just like a view, a mountain or a bay, wine and food are aesthetic objects and likewise a painting or a sculpture they are artistic objects. Wine and its accompanying good will add additional values such as synergy. The dance of wine and food is worth watching. For the final taste, the effects of the pairing parties can never be determined.

There are differences between good wines and great wines. Good wine means it is a little more than drinkable one in comparison to normal wine. However, the great wines offer a unique complex bouquet and most of the time the same exact bouquet cannot be reproduced. There are various descriptions of quality, but Simon's (1969) description stipulates quality as a "result of the happy partnership between soil, vines, and climate”. Drinking fine wine provides an occasion for pleasure and also an opportunity for thought. As Latins said, "in vino veritas" literally means in wine there is truth. Socializing and conversation will happen around oenogastronomic activities. This is a very crucial touristic event in the sense that wine helps people to overcome the social stress and to socialize better. This is a cycle of action and reaction. 
It is possible to have different experiences of wine. For example, Tokai region in Hungary produces grapes which are grown in volcanic areas. The wine produced in that region gives people a feeling with a volcanic taste. Is it important? If people do not have such an experience before, that is going to be a new one for them. This directly affects the tourists' QOL. Wine and food tourism is in many ways related with QOL. By getting acquaintance with new cultures and tastes, tourists gain different perspectives. The tastes of delicious goods give them pleasure, a different pleasure than other tourism activities can offer. The tourists of oenogastronomic tourism are getting pleasure, getting curious, sharing, and feeling the adventure of tasting the new. In the past, concentrated wines were produced. The drinking and consumption period of wine had been on a table where there was a head person. This head person gave orders for the dilution of the wine according to the general mood. The atmosphere of the moment, conversations around the table, and effects of wine on the socializing were watched by this head person. Now this limitation is done according to different factors such as price, quality, social and legal boundaries.

Most of the Mediterranean destinations offer similar elements, namely, sun, sea, and sand (3S). When marketing tourism, destinations can use their oenogastronomic differences as unique and authentic elements of the culture which make them distinguished instead of offering this common $3 \mathrm{~S}$ in order to gain some competitive advantages. Tiramisu from Italy, ouzo and retsina wine from Greece, and yoghurt and kebab from Turkey, of course not forgetting local wines, are some examples.

Food and wine tourism enables a re-qualification of a tourism offer. There is an opportunity to promote a new place with food and wine tourism. As a matter of fact, tourism is ready to reborn not only in definition but also in the application. As it is clear in the history of tourism, in some cases, tourism is reborn from its ashes (i.e., Chernobyl). "Food \& wine tourism can facilitate tourists to see the world in an optimistic way. Since it is the fact, by doing so the whole tourism experience will be different” (Croce \& Perri, 2010).

"Tourism that takes full account of its current and future economic, social and environmental impacts, addressing the needs of visitors, the industry, the environment and host communities” (UNWTO, 2014). As a destination takes the role of a tourist product and becomes a source of attraction, if it is not organized well, there is going to be an abusing problem and a problem of lost product will appear. If we aim to enjoy what we are enjoying today also in the future furthermore allow next generations to enjoy if not more we should develop a sustainable attitude towards our consumption and production. That is the reason why no matter what we are doing, sustainability should be the main concern. Economic sustainability comes from the fact that touristic activity is an economic activity in many ways. Tourists add value, spend time pleasantly, contribute to their cultural and personal developments and at the same time engage in an economic activity (Genç, 2014a; 2014b). Tourism quality and sustainability together enhanced the QOL of the visitors of today and tomorrow. At the same time, sustainability is a part of our social responsibilities. Tourism product's success cannot be measured by economic terms only. The major principle is tourist's sense of belonging to the destination and the increase of their sense of responsibility with the sense of well-being.

\section{Socio-Cultural Basis of Food Habits Makes People’s Travel Itinerary}

Lowenberg's (1970) adaptation of Maslow's hierarchy of needs on F\&B consumption makes it easier for us to understand the relationship between the hierarchical steps (see Figure 3). Oenogastronomical experience is different from normal F\&B consumption in a way that tasting new bouquet and flavors becomes the major motive of such a step. It is also a sign of social status, especially when F\&B items and/or their serving places embody a status symbol. 
Oenogastronomic tourist is a consumer who is trying to fulfill his/her hedonic needs and desires. The tourist interprets consumption as a means to increase his/her QOL.

Designing a tour is conditioned by various factors like personal preferences, accommodation facilities, and other services in the areas, budgets, etc.. As we can see in Figure 4, a good example of a daisy route itinerary is a gastronomic tour of San Francisco visiting various restaurants where people can see how east and west meet. If people want to enjoy Asian culture and oenogastronomic values, they can cross the Golden Gate Bridge and visit China Town and/or Japanese quartier. On the other hand, if they want to visit where the wine comes from, Napa Valley is only an hour away. People can spend a couple of days where they can visit and stay various vineries. If their flight is to and from San Francisco, they may choose that city for their first and last day sojourn for visiting the city which gives them little time to enjoy.

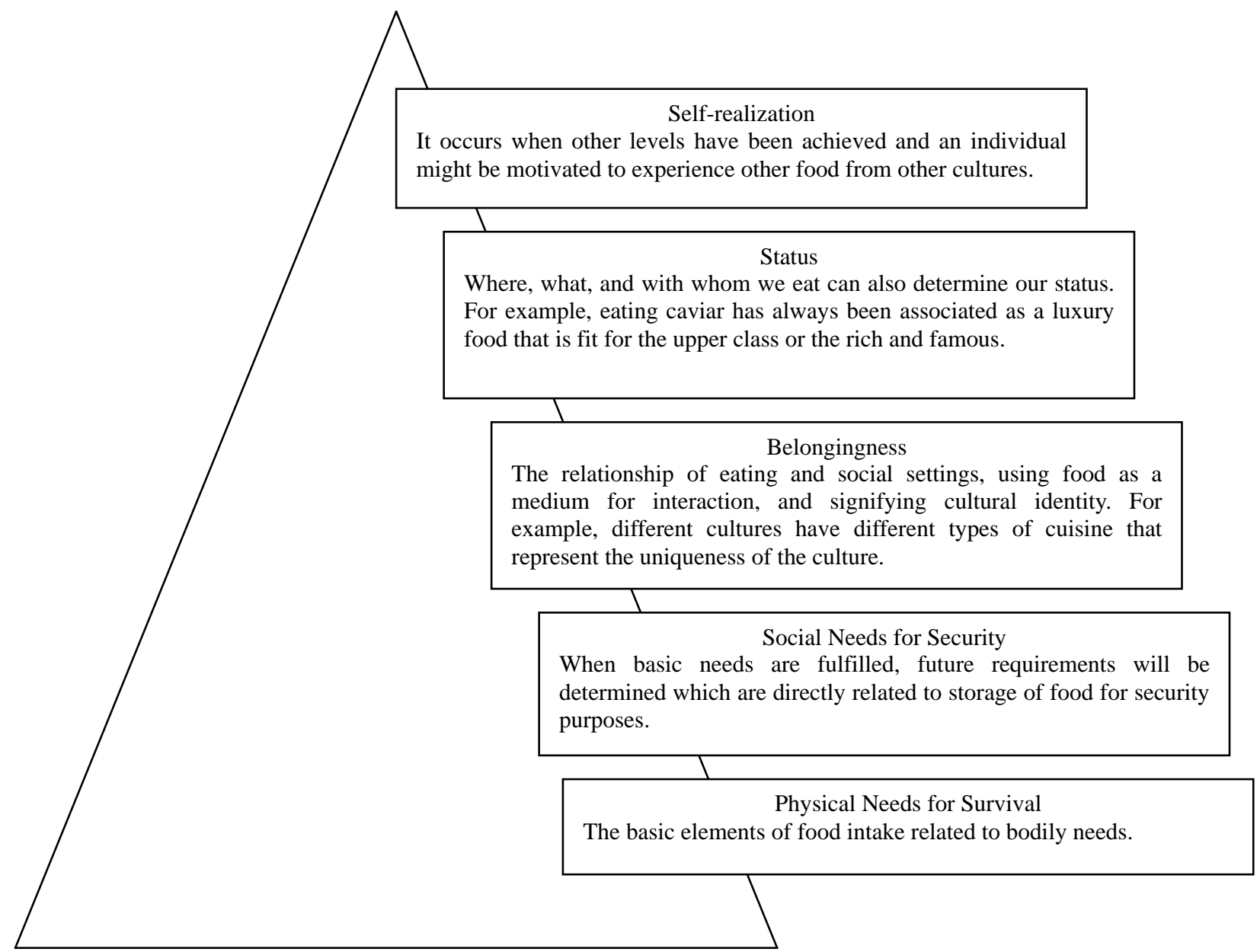

Figure 3. Socio-cultural basis of food habits. Source: Lowenberg (1970).

Circuit route can include all the basic oenogastronomic points, starting from one city, i.e., San Francisco and Napa Valley from there to Disney World (Orange County), Hollywood, Los Angeles, and a departure from there.

Branch route can be planned like coming to and visiting San Francisco with a small side trip to Napa Valley and continue on to Las Vegas where people can see heaven built on the desert and depart from Las Vegas. 
Linear route can be planned as coming to San Francisco and then going to Napa Valley, Las Vegas, and Los Angeles and staying a day or two in each destination, departing from the last destination. As one can understand easily from the name, mixed itinerary consists of overnight stays in the same arriving and departing city, let's say San Francisco. After arrival, there will be staying for a couple of days, taking an excursion to Napa Valley before going to Las Vegas where people can have side trips, excursion to various points to enjoy and fulfill their oenogastronomic needs with the cultural and historical richness and then taking a next step to Los Angeles. Before they go to San Francisco, they may stay another day or two to visit some missing points in their itinerary and then get ready for their departure.

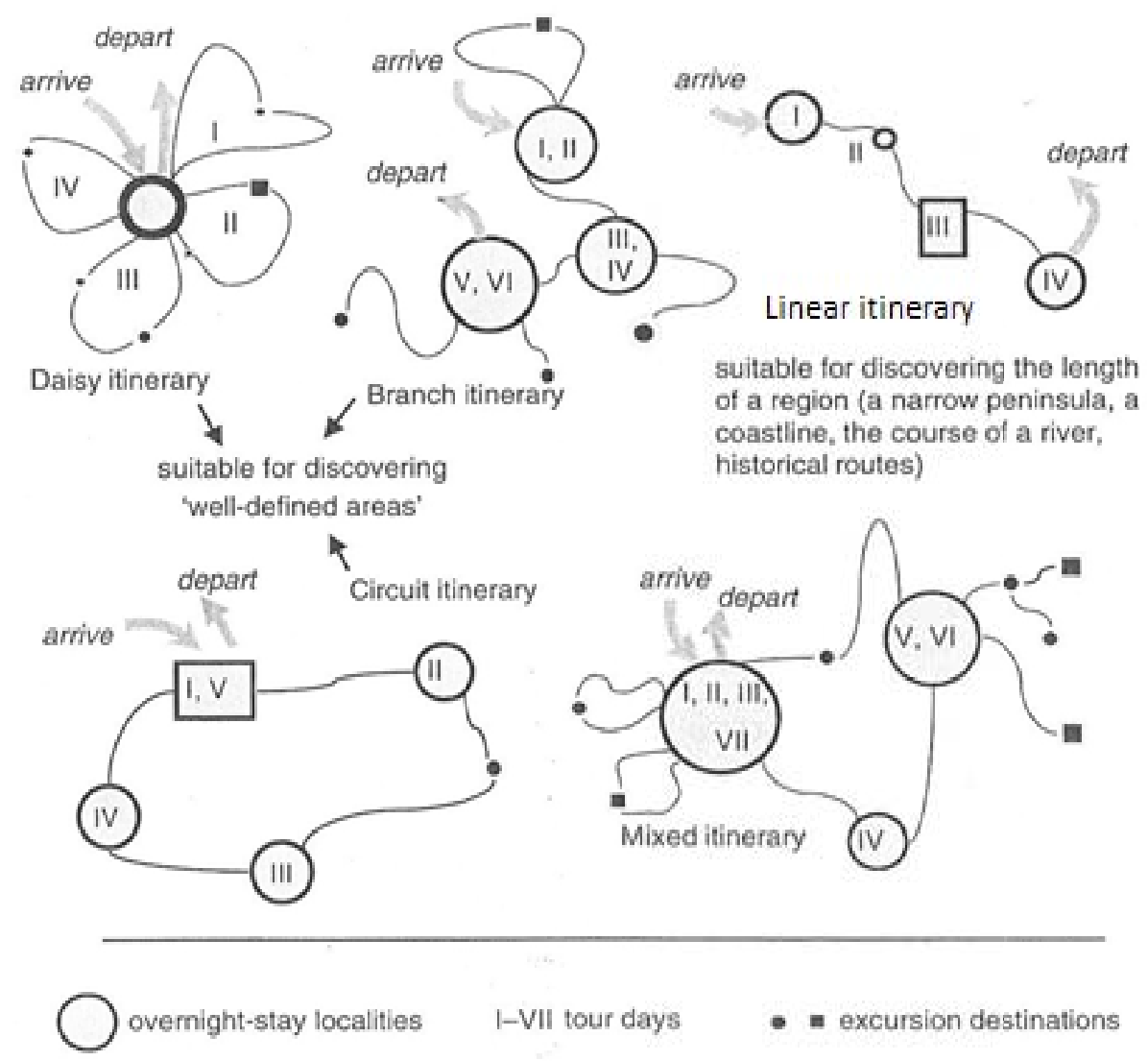

Figure 4. Different regions: choosing the best format. Source: Croce and Perri (2010).

\section{From Terroirs to Destinations}

The product acts as a bridge between the needs of the demand. For transforming a terroir with its resources into a tourist destination, managerial steps should be taken as follows:

(1) The terroir and its potentials should be measured and described. The composition and number of potential tourists should be well calculated for possible evaluation;

(2) Potential tourists' expectations should be seized and evaluated if the areas' potential can give satisfying results;

(3) Chefs and farmers must be given the chance to come together. They are in the key position for the taste and quality of F\&B so their contact and suggestions or even their collaboration will have fruitful consequences;

(4) Well-fitted strategies should be chosen and had to be made applicable; 
(5) Alternative strategies and their application should be developed in order to choose the best suitable one and all the details of the destination, whether they are seen or unseen, should be discovered and pointed out for possible marketing strategies.

Terroirs have significance in viticulture in the sense that it is the place where the production of wine starts. The socio-economic conditions with all the technical issues enable the terroir to become a destination. The precocity of the grapes, climate conditions, soil type and ingredients, and the precise amount of inducements are respected factors in analyzing the concept of terroir. Because of the fact that in several weather conditions it is possible to produce wine, developing a terroir is not hard on the condition that there are suitable conditions. While very high quality wines are grown in various climates, it is impossible to define the ideal climate for fine wines in terms of temperature, rainfall (amount and distribution), or solar radiation. Nor can one define the best possible soil for growing high-quality wines in terms of pebble, clay or lime content, soil depth, or mineral content. These factors of the natural environment have to be considered in terms of their interaction with the vine (Van Leeuwen \& Seguin, 2006).

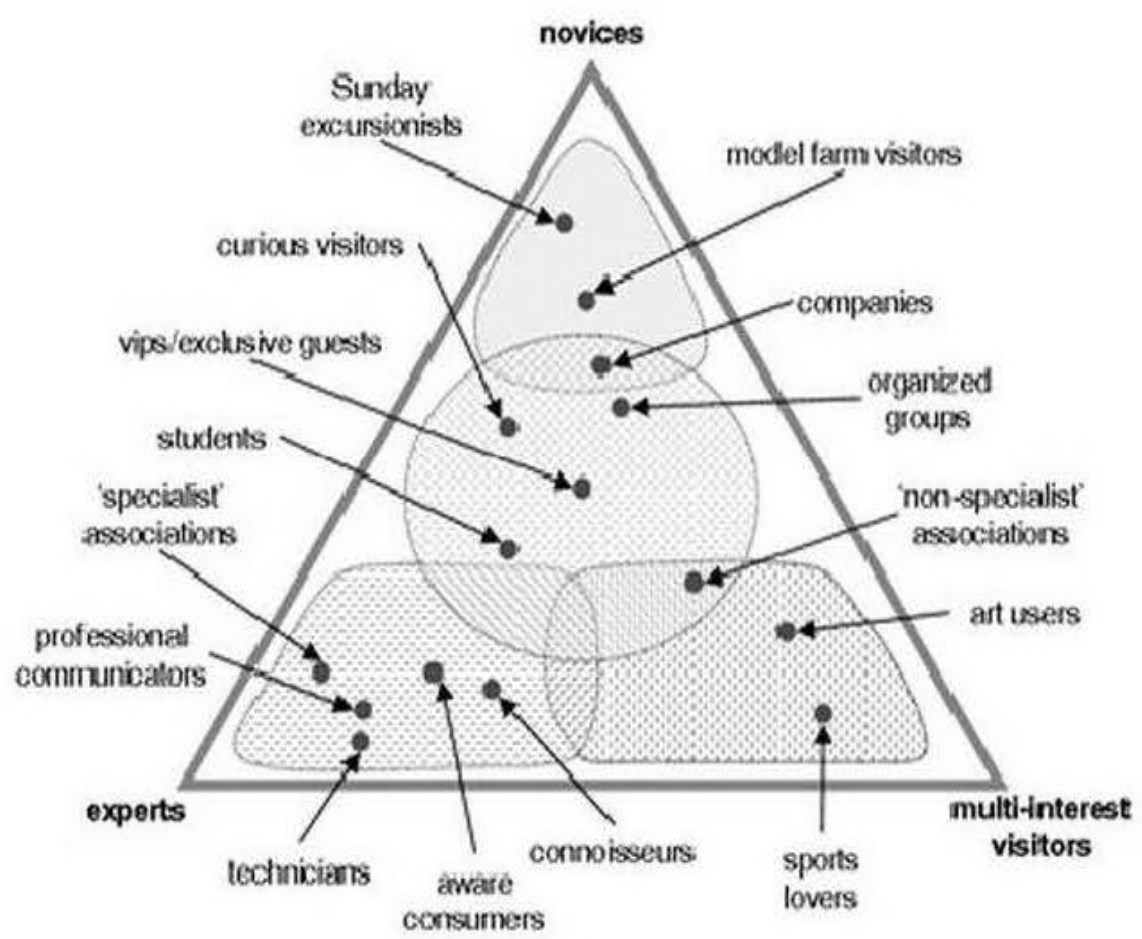

Figure 5. Food and wine tourists: a pyramid of different types. Source: Croce and Perri (2010).

A market breakdown can be shown in the pyramid in Figure 5 by analyzing the degree of awareness about the food and wine. In the diagram, one can see the degree of awareness about the food and wine, specialization of interest and knowledge. There are tourists who rarely or coincidently visit food and/or wine producing areas and have no or little interest for those items. On the other hand, there are experts who are knowledgeable about oenogastronomy and their main motives of visiting the area are to have new oenogastronomic experiences. If they have time to share other activities they may do so, otherwise they will be fully satisfied, if they only visit F\&B facilities before they complete their tours. Multi-interest visitor groups enjoy combining more than one activity in one trip for personal or due to accompanying group members' interests. 


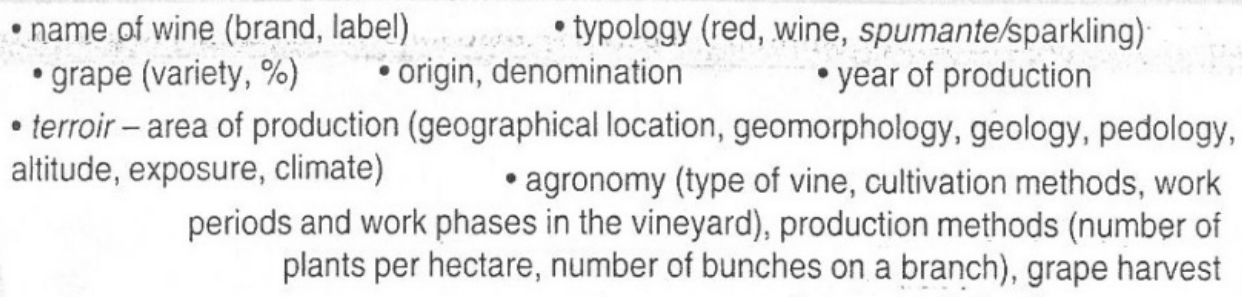

environment, landscape, history, art, people and society, economy, identity, traditions, stories and anecdotes, other resources, latest news, the future

Figure 6. A total experience: discovering wine and its region of origin through words and images. Source: Croce and Perri (2010).

Technicians are quite knowledgeable about one or two specific production. They visit competitors to understand their own products. For them, such visits mean a comparative study and sometimes a good reason to reshape themselves. They visit more than one place in their interest direction, most of the time extreme ones to gather best segmentation possible for their own studies. The members of specialist associations belong to national and/or international bodies like Wine Lovers Association, Chaine des Rotiseurs. They regularly participate professionally designed tasting within their own rituals. These participations increase the knowledge of participants while supporting more powerful ties between cultures and sectors also the country fosters group ties. Connoisseurs have good knowledge about food and wine and they enjoy learning more and 
more while they are visiting related destinations. Curious visitors are interested to know more about food and wine and they show interest to learn by experiencing new culinary art samples. Students are visiting either out of their interest or as an application of their own knowledge. Since there are other groups in the chart such as model farm visitors, companions, sports lovers, art users, Sunday excursionists, aware consumers, "non-specialist” associations, organize groups, VIPs/exclusive guests, professional communicators, their group names are self-explanatory. There are quite a few books written showing the connection between taste and terroir. Special difficulties can be pointed out for countries like the United States where, on average, any food has travelled at least 1,500 miles from farm to table (Trubek, 2009). The scale of analysis by area ranges from local to abroad spatial coverage: local functional approaches emphasize quality controlled by ecology and physiology: spatial approaches depend on the diversity of viticultural environments from area to area (Vaudour, 2002). That is the reason why it does not need any further explanation for the purpose of the paper.

Although tourists' expectations and inclinations differ, the transformation of terroirs into destinations may by accelerated by two ways: making trips to terroirs for the ones who are already willing to visit a terroir and endearing the terroirs in the eyes of the tourists (see Figure 6 above). The first attracts the specialists, technicians and the like in order to deepen their knowledge and experience. The latter will be managed through promoting the processes in the terroirs as cultural tourism. Since culture, as a learned concept, guides individuals and determines appropriate and accurate behaviours and attitudes, it functions to form a common ground and helps different symbols to have similar meanings for all members. Not only experts but also the ones who like cultural tourism and wine will enjoy a touristic trip to a terroir if the terroir is organized for a touristic activity.

The tasting of wine offers the opportunities for not only visitors but also producers. Integrating small- and medium-sized enterprises (SMEs) into tourism Global Value Chains (GVCs) remains a challenge. Participation in GVCs requires a high level of coordination across industry stakeholders in the public, private, and even non-profit sectors in order to ensure that interests are aligned, skill gaps are closed, and structural constraints are addressed (OECD, 2014). A taster can have a good idea about production methods and procedures while they are having various known and unknown tastes. If the entertainer used correct strategies for learning, then it is possible to make a healthy connection among product, environment, history, culture, art, economy, stories behind, hidden factors even philosophy. With people far more sophisticated about wine than they used to be inevitably those who take a serious interest in wine find themselves asking questions about it that are at heart philosophical (Smith, 2009). By stressing the product's link with the environmental factors, visitors can have a complete experience for the region through the wine.

Hall and Sharples (2003) explained the relations and differences between F\&B consumption and oenogastronomic trend in tourism palate. The $\mathrm{x}$-axis shows the importance of the $\mathrm{F} \& \mathrm{~B}$ activities, while the $\mathrm{y}$-axis shows the number of participating tourists (see Figure 7).

Quadri-Felitti and Fiore (2012) offered a model (see Figure 8) adapted from Pine and Gilmore theory to explain the experimental nature of wine tourism. The result of the study demonstrates that on one hand, an aesthetic experience is the main expectation, escapist and educational experiences are the least important on the other hand. 


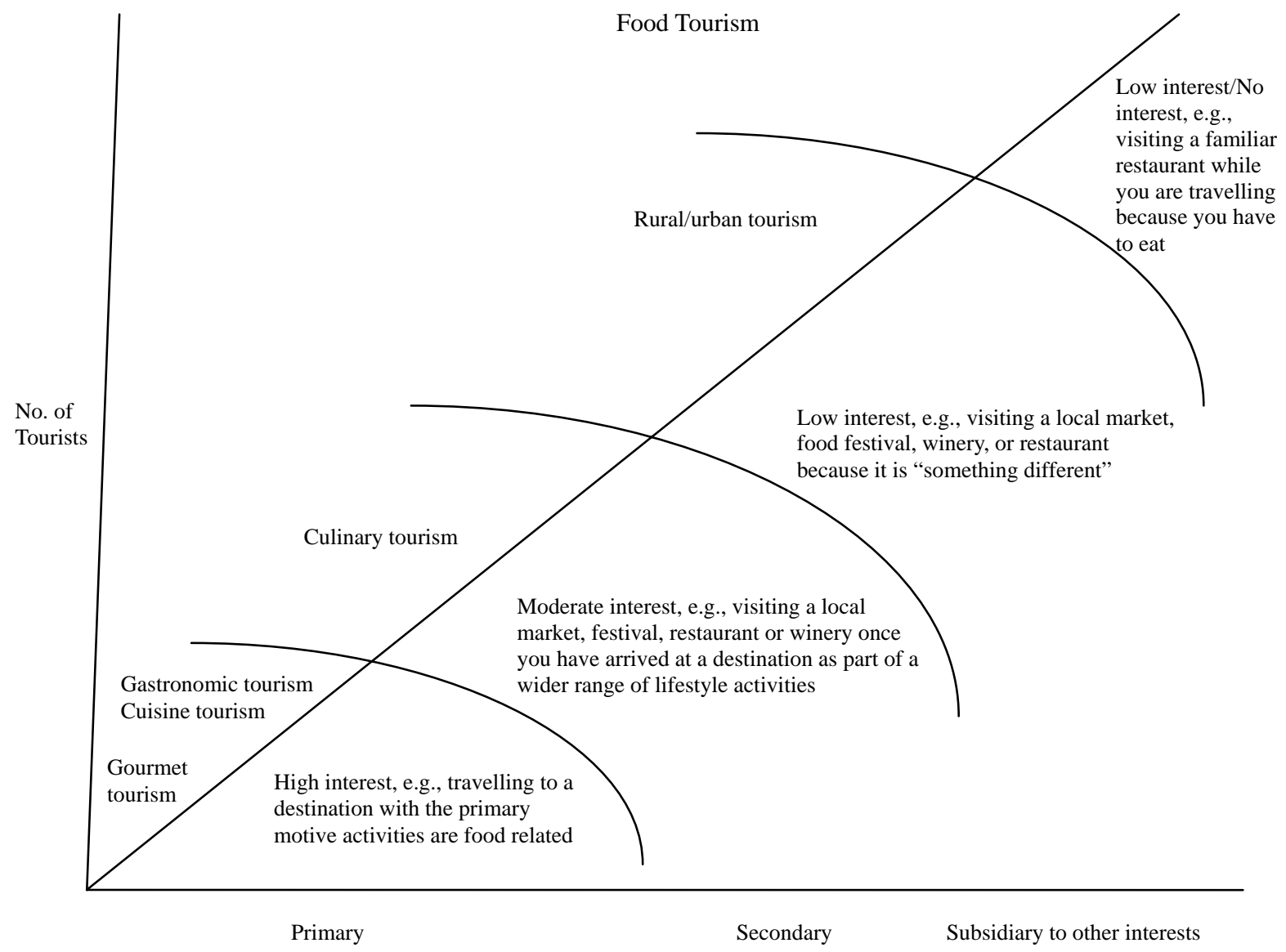

Figure 7. The importance of a special interest in food as a travel motivation. Source: Hall and Sharples (2003).

\section{Entertainment}

Tourists are engaged by performances.

- Cellar concerts, music in vineyard

- Wine blending demonstration

- Farm \& food demonstrations

- Museum \& heritage site visits

\section{Educational}

Tourists enhance their knowledge or skills.

- Wine tastings \& seminars

- Culinary-wine pairing events

- Home wine making seminars

- Cooking \& craft making classes

\section{Escapist}

Tourists become engrossed by participating in a different time or place.

- Vineyard hiking, cycling tours

- Hot air ballooning over vineyards

- Vineyard tour by horse \& carriage

- Harvesting grapes, riding a grape picker
- Enjoying unique lodging (B\&B) and wines

- Driving rural roads lined with vineyards

- Art \& craft fairs at wineries

Figure 8. Typical wine tourist activities shown within the 4E model of the experience economy. Source: Quadri-Felitti and Fiore (2012). 


\section{Conclusion}

Oenogastronomy consists of tourism demand and focuses on eating and drinking wine. When traveling with others, co-travelers' needs and desires might also come into the scene. By doing so, one type of tourism will increase and stimulate other activities at the same time. Since all of these activities will be materialized within a region, this region (terroir) might become a well-known destination. Such combination means ever increasing demand. Using a multi-disciplinary approach is a vital part of a creative result. There are a number of oenogastronomic destinations where competition increases the quality-price ratio.

Innovation and sustainability are better established with oenogastronomy, and eco-wine and eco-food are respectable concepts in this sense. When food and wine are the main objectives of a tour, some group members enjoy it while others might get bored. If we enrich the tour with a cultural attraction, the added value of the whole activity will likely be greater. Whether we are dealing with F\&B only or planning to have some side trips enhancing the value of the main attraction, the two concepts give a great added value for tourism and its future. The multi-disciplinary character of the oenogastronomy tourism will fortify all other sectors within the related areas. In other words, it is going to be a locomotive for the regional development because it has the potential. Also, it has a special place in tourism activities. Tasting F\&B happens to be a different touristic experience for the visitors.

Generally speaking, studies made for tourism intend to find some results which might be useful for the sector. Sometimes, results will enlighten the stakeholders' path for them to become more productive and/or to be innovative as it has been demonstrated, for example, in Campania, wine industry, Italy (Rossi, Vrontis, \& Thrassou, 2012). This study shows the importance of oenogastronomy and all the other activities in vicinity. In wine-producing areas, decision-makers can create a destination which enables some sight activities to make it more profitable.

Oenogastronomic tourism combines scales, expertise, and innovation, and an appropriate combination of these three elements will increase the demands. When it comes to the very first motive that created this paper, we conclude that: In an interactive context, factors trigger each other reciprocally so that oenogastronomy attracts and enriches tourism and tourism attracts oenogastronomy.

\section{References}

Croce, E., \& Perri, G. (2010). Food and wine tourism: Integrating food, travel, and territory. UK: CABI.

Genç, R. (2012a). Tourist consumption behavior and quality-of-life. In Handbook of tourism and quality-of-life research (pp. 135-148). The Netherlands: Springer.

Genç, R. (2012b). Subjective aspects of tourists' quality-of-life (QOL). In Handbook of tourism and quality-of-life research (pp. 149-167). The Netherlands: Springer.

Genç, R. (2014a). International hotel and restaurant management modern approaches. Createspace.

Genç, R. (2014b). Sustainable strategies for destination management. Acta Universitatis Danubius, Oeconomica, 10(3), 91-101.

Gilbert, D., \& Abdullah, J. (2004). Holidaytaking and the sense of well-being. Annals of Tourism Research, 31(1), 103-121.

Hall, C. M., \& Sharples, L. (2003). The consumption of experiences or the experiences of consumption? An introduction to the tourism of taste. In C. M. Hall, L. Sharples, R. Mitchell, N. Macionis, \& B. Cambourne (Eds.), Food tourism around the world: Development, management, and markets (pp. 1-24). Oxford: Butterworth-Heinemann.

Lewinsohn, P. M., Redner, J., \& Seeley, J. R. (1991). The relationship between life satisfaction and psychosocial variables: New perspectives. In F. Strack, M. Argyle, \& N. Schwartz (Eds.), Subjective well-being: An interdisciplinary perspective (pp. 141-169). Oxford: Pergamon Press.

Lowenberg, M. E. (1970). Socio-cultural basis of food habits. Food Technology, 24, 27-32.

OECD. (2014). Retrieved from http://www.oecd.org/ 
Plog, S. C. (1991). Leisure travel: Making it a growth market.... again! New York, NY: John Wiley \& Sons, Inc..

Quadri-Felitti, D., \& Fiore, A. M. (2012). Experience economy constructs as a framework for understanding wine tourism. Journal of Vacation Marketing, 18(1), 3-15.

Rossi, M., Vrontis, D., \& Thrassou, A. (2012). Wine business in a changing competitive environment - Strategic and financial choices of Campania wine firms. International Journal of Business and Globalisation, 8(1), 112-130.

Simon, L. A. (Ed.). (1969). Wines of the world. New York, NY: McGraw-Hill.

Smith, C. B. (Ed.). (2009). Questions of taste: The philosophy of wine. UK: Oxford University Press.

Swarbrooke, J., \& Horner, S. (1999). Consumer behaviour in tourism. Burlington: Butterworth-Heinemann.

Trubek, A. B. (2009). The taste of place: A cultural journey into terroir (Vol. 20). Berkeley: University of California Press.

UNWTO. (2014). Tourism highlights.

Van Leeuwen, C., \& Seguin, G. (2006). The concept of terroir in viticulture. Journal of Wine Research, 17(1), 1-10.

Vaudour, E. (2002). The quality of grapes and wine in relation to geography: Notions of terroir at various scales. Journal of Wine Research, 13(2), 117-141. 